\title{
EXPERT
}

\section{Increasing costs from bladder cancer in the Brazilian Health System: the role of establishing public health policies}

\author{
Fernando Korkes ${ }^{1,2}$, Fernando Maluf ${ }^{3}$
}

${ }^{1}$ Disciplina de Urologia, Faculdade de Medicina do ABC, Santo André, SP, Brasil; ${ }^{2}$ Departamento de Urologia, Hospital Israelita Albert Einstein, São Paulo, SP, Brasil; ${ }^{3}$ Hospital da Beneficencia Portuguesa de São Paulo, São Paulo, Brasil

\section{COMMENT}

$\mathrm{BC}$ number and treatment advances

Bladder Cancer (BC) is not a very common malignancy. In Brazil, there are 10.640 new cases estimated for 2020, representing $1.6 \%$ of all malignancies $(1,2)$. In Brazil, aging population has been associated with a significant increment in the number of patients with $\mathrm{BC}$ during the last decade (3). During this period, an increment of $44 \%$ in the number of hospital admissions due to $\mathrm{BC}$ have occurred (3). Apart from that, unfortunately, treatment of the initial phases of $\mathrm{BC}$ is complex and underperformed in the public health system (SUS) (4). The main reasons are the limited access to the initial evaluation, diagnosis, initiation of treatment, and treatment availability, resulting in a significant number of patients with more advanced disease (3). BCG shortage is another worldwide problem associated with more disease progression to advanced disease.

Fortunately, during the last years, we have witnessed significant advances in new treatments for this disease. Immunotherapies, targeted therapies, diagnostic and staging tests, and several local technologies have been associated with lifespan and quality of life improvements for these patients (5). In the last three years, five immunotherapies (avelumab, atezolizumab durvalumab, pembrolizumab, and nivolumab) and one targeted therapy (erdafitinib) have been approved for the treatment of patients with BC (5). These medications can now be used in a variety of scenarios, from non-muscle invasive to first-line metastatic, maintenance or second-line metastatic treatments. Furthermore, there are also new medications being approved (5, 6). There is no doubt that we can now treat these $\mathrm{BC}$ patients better and better.

\section{Costs with $\mathrm{BC}$ treatment}

However, these scientific advances come at high costs (Table-1). Despite its relatively low frequency, BC treatment is associated with elevated expenses. It is one of the malignancies with the highest lifetime treatment costs per patient (7). In the USA, it is estimated that US $\$ 4$ billion are spent each year to treat BC (8). And these exceedingly high expenses were calculated when most BC treatments were significantly cheaper than they are today (Figure-1). Not only are the medications associated with a remarkably higher monthly cost, but they are also used for significantly longer periods. This costs to the SUS can exponentially increase, and here are some of the reasons.

Judicialization in the SUS

Fortunately, in Brazil, health is a citizen's fundamental right guaranteed by the Constitution of 1988. The Universal Health System (Sis- 
tema Único de Saúde - SUS) was created to treat every single Brazilian that need healthcare. Despite advances brought by this Constitutional right, many treatments are not promptly incorporated into the routine care in the public system. In such a context, some citizens search for federal courts to obtain new and costly medications. The so-called judicialization of health involves court decisions that require the government to provide health products and services based on the Constitutional right to he-

Table 1 - Predicted cost increments on bladder cancer treatment.

\begin{tabular}{|c|c|c|}
\hline Reason to increase costs & & Cost increment \\
\hline Number of $\mathrm{BC}$ cases & $\begin{array}{l}\text { yearly increment of } 23 \% \text { during the last decade in Brazil; } \\
\text { (3) }\end{array}$ & $23 \%$ \\
\hline Cost of treatment/patient & $\begin{array}{c}\text { increased } 2.367 \% \text { (from } \mathrm{R} \$ 40.177 .00 \text { to } \mathrm{R} \$ 951.071 .20 \text { ) } \\
\text { if we follow the recent advances in life expectancies } \\
\text { observed in recent studies with immunotherapeutics in } \\
\text { metastatic disease (13) }\end{array}$ & $2.367 \%$ \\
\hline Judicialization in SUS & Increased at a $30 \%$ / year in the last years (14) & $30 \%$ \\
\hline Costs of buying individually & $\begin{array}{l}\text { Costs of medication bought individually and not in large } \\
\text { scale are four times higher. }\end{array}$ & $400 \%$ \\
\hline TOTAL increment & $\begin{array}{l}\text { Potential increment in costs with } \mathrm{BC} \text { treatment during } \\
\text { the next years }\end{array}$ & $15.141 \%$ \\
\hline
\end{tabular}

Figure 1 - FDA (USA Food and Drug Administration) approved medications to treat BC currently available in Brazil and their estimated costs in $\mathbf{R}$ in 2020. In gray medications available before 2016. In red, medications available since 2016.

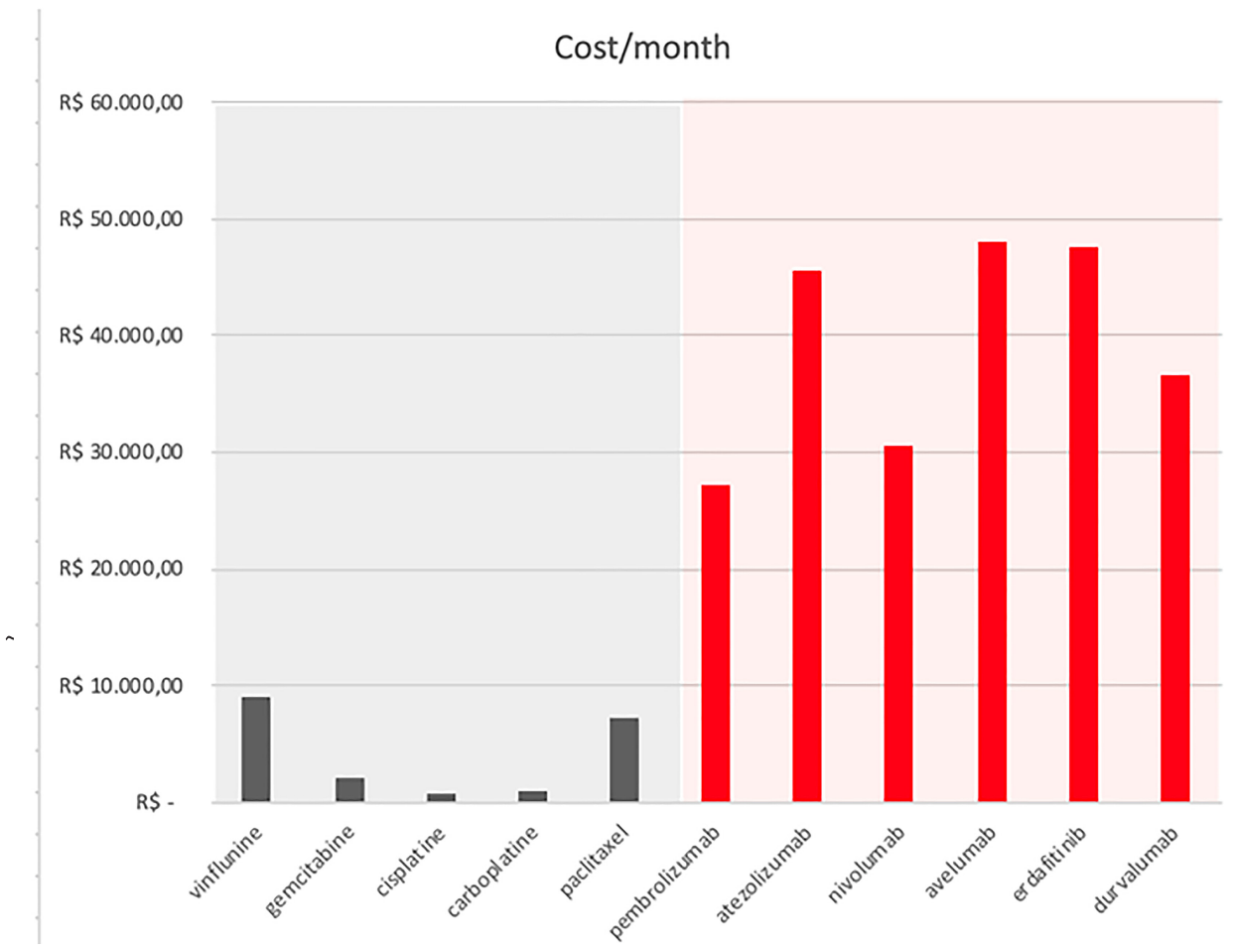

Font: Site https://consultaremedios.com.br. Estimated values for a $70 \mathrm{Kg}$ adult. 
alth. And these lawsuits are considered a significant challenge for the SUS (9).

Even though healthcare judicialization in the SUS has its social and positive role, it also brings significant financial consequences to the Union and to society. In 2019 there were 2.228.531 health-related lawsuits in Brazil. Of those, 980.975 (44\%) were motivated by granting access to medications or treatments in the public health system (SUS) (9). During the last eight years, the number of health-related lawsuits has increased astonishing 925\% (Figure-2). The public expenditures with health-care judicialization have increased 4.600\% from 2007 to 2018 (9). In 2018, the Health Ministry was forced to spent R\$1.3 billion through judicialization to treat only 1.300 patients. This number represents more than $1 \%$ of the SUS annual budget. Among the 20 drugs that represent the higher expenditures for the SUS through judicialization, seven are associated with cancer treatment, and the National Commission incorporated none of them for the Incorporation of Technologies to the SUS (CONITEC) (9).

There is no doubt that requests for new innovative products offered by the pharmaceutical industry pose a significant challenge for the public health system. Nevertheless, there are means that patients can have access to these effective medications. It is fundamental to balance individual rights with society's necessities and, more importantly perform a cost-effective analysis. Moreover, there are several possible solutions to these problems.

Possible solutions

Centralization programs have been proven to reduce costs and improve outcomes when treating BC (10). Creating reference centers is beneficial not only for the treatment of an individual patient but also for bringing these patients to centers where more strict protocols can be followed (11). New medications can be prescribed when they are beneficial, but judicialization tends to be lower in this setting (9).

Additionally, creating and following strict protocols can help to predict costs. The dynamic inclusion of new drugs to the SUS is essential in the development and approval of new therapies. SUS does not have established protocols for the treatment of most diseases. This flaw favors judicialization. With judicialization, public managers cannot predict the health budgets and might need to relocate provisioned resources. On the other hand, costs for acquiring medications in a large scale are about four times lower than buying individual medications. With provision and scale, negotiations with the pharmaceutical industry could lower even more these costs. Also, there are many mathematical models to lower drug costs, such as payment only when the medication has provided clinical benefit such as the example implemented with spinal muscle atrophy. Also, the government

Figure 2 - Health-related lawsuits in Brazil from 2011 to 2019 (15).

\section{Number of health-related lawsuits in Brazil}

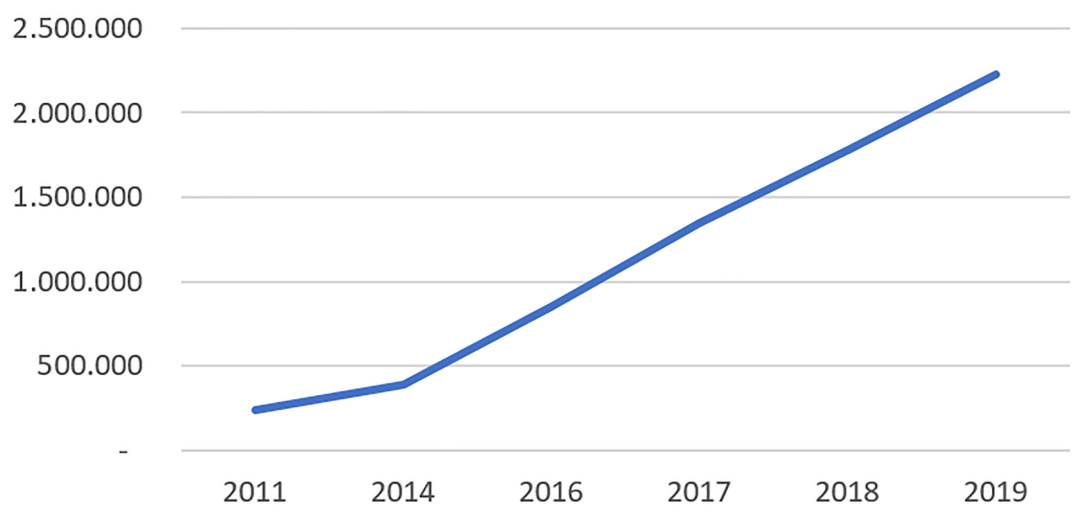


can buy generic drugs when they are available, and in the event they are not, negotiate with the pharmaceutical companies to buy that specific drug according to the lower price rate worldwide.

Clinical Trials are also always an attractive solution for patients with advanced cancer. Fomenting and international trials to come to Brazil can lower the burden of BC's treatment. They help to reduce costs to the system and contribute to the progress of science. In this regard, cooperative groups such as the Latin American Oncology Cooperative Group has been launched many protocols in solid tumors such as bladder cancer (12).

Even though BC is relatively uncommon, it is expensive. Furthermore, there is a paucity of public health policies aiming at these patients. The Union and the medical society must sum efforts to assess this situation. Otherwise, the combination of increments in $\mathrm{BC}$ cases, treatment costs, and judicialization can lead to a collapse in the SUS shortly.

\section{CONFLICT OF INTEREST}

None declared.

\section{REFERENCES}

1. Estimativa 2020. Brasil - estimativa dos casos novos. MINISTÉRIO DA SAÚDE, Institutp nacional de Câncer 2020. [Internet]. Available at. <https://www.inca.gov.br/estimativa/ estado-capital/brasil>. Accessed Jul 02, 2020

2. Korkes F, Palou J. High mortality rates after radical cystectomy: we must have acceptable protocols and consider the rationale of cutaneous ureterostomy for highrisk patients. Int Braz J Urol. 2019; 45:1090-3.

3. Timoteo F, Korkes F, Baccaglini W, Glina S. Bladder cancer trends and mortality in the brazilian public health system. Int Braz J Urol. 2020; 46:224-33.
4. Reis LO, Moro JC, Ribeiro LF, Voris BR, Sadi MV. Are we following the guidelines on non-muscle invasive bladder cancer? Int Braz J Urol. 2016; 42:22-8.

5. Witjes JA, Bruins HM, Cathomas R, Compérat EM, Cowan NC, Gakis G, et al. European Association of Urology Guidelines on Muscle-invasive and Metastatic Bladder Cancer: Summary of the 2020 Guidelines. Eur Urol. 2020;29:S03022838(20)30230-X. Epub ahead of print.

6. FDA Approves Padcev (Enfortumab vedotin-ejfv) for Bladder Cancer. American Cancer Society 2019. [Internet]. Available at. <https://www.cancer.org/latest-news/fda-approvespadcev-enfortumab-vedotin-ejfv-for-bladder-cancer.html> Accessed Jul 02, 2020.

7. Sievert KD, Amend B, Nagele U, Schilling D, Bedke J, Horstmann $\mathrm{M}$, et al. Economic aspects of bladder cancer: what are the benefits and costs? World J Urol. 2009; 27:295300.

8. Park JC, Hahn NM. Bladder cancer: a disease ripe for major advances. Clin Adv Hematol Oncol. 2014; 12:838-45.

9. Chieffi AL, Barradas RCB, Golbaum M. Legal access to medications: a threat to Brazil's public health system? BMC Health Serv Res. 2017; 17:499.

10. Afshar M, Goodfellow H, Jackson-Spence F, Evison F, Parkin J, Bryan RT, et al. Centralisation of radical cystectomies for bladder cancer in England, a decade on from the 'Improving Outcomes Guidance': the case for super centralisation. BJU Int. 2018; 121:217-24.

11. Hamad J, McCloskey H, Milowsky MI, Royce T, Smith A. Bladder preservation in muscle-invasive bladder cancer: a comprehensive review. Int Braz J Urol. 2020; 46:169-84.

12. Soares A, Carvalho I, Bastos DA, da Rosa DAR, Maluf FC, Adamy Junior A. Brazilian consensus in muscle-invasive and metastatic urothelial carcinoma.Brazilian Journal of Oncology 2020;16. [Internet]. Available at. <http://www. brazilianjournalofoncology.com.br/details/111/en-US/ consenso-brasileiro-em-carcinoma-urotelial-musculoinvasivo-e-metastatico>.

13. Powles T, Park SH, Voog E, Maintenance avelumab + best supportive care (BSC) versus BSC alone after platinumbased first-line (1L) chemotherapy in advanced urothelial carcinoma (UC): JAVELIN Bladder 100 phase III interim analysis. MDlinx [Internet]. Available at. <https://www. mdlinx.com/journal-summary/maintenance-avelumabbest-supportive-care-bsc-versus-bsc-alone-after-platinumbased-first-line-11/7rvLXIQnqVCOidUaTieEpD> 
14. Britto A, Mezei V.Por que o brasileiro recorre à Justiça para adquirir medicamentos? Interfarma. 2016. [Internet] Avaliable at. <https://www.interfarma.org.br/public/files/ biblioteca/101-por-que-o-brasileiro-vai-a-justiaa-em-buscade-medicamentos-site.pdf>

Fernando Korkes, MD, PhD

Departamento de Urologia,

Hospital Israelita Albert Einstein, São Paulo, SP, Brasil

Rua Iguatemi, 192 / 23

São Paulo, SP, 01451-010, Brasil

Telephone: + 5511 3168-5995
15. Schulze CJ. Números de 2019 da Judicialização da Saúde no Brasil - Empório do Direito. 2019. [Internet]. Available at. $<$ https://emporiododireito.com.br/leitura/numeros-de-2019da-judicializacao-da-saude-no-brasil>.

ARTICLE INFO

iD Fernando Korkes http://orcid.org/0000-0003-4261-4345

Int Braz J Urol. 2020; 47: 443-7

Submitted for publication:

July 24, 2020

Accepted:

October 10, 2020 